\section{Como funciona a propaganda? Ideologia, demagogia $e$ desigualdade}

\section{How Propaganda Works? Ideology, demagogy and inequality}

STANLEY, Jason. How propaganda works? Princeton, Princeton University Press, 2016. 353 páginas.

\section{Renato Francisquini}

http://orcid.org/0000-0003-2789-457X

Universidade Federal da Bahia (UFBA), Salvador - BA, Brasil. E-mail: renato.francisquini@ufba.br

DOI: $10.1590 / 3410101 / 2019$

"Esta permanecerá sempre como uma das melhores piadas da democracia, que ela tenha dado aos seus inimigos mortais os meios pelos quais ela foi destruída." ${ }^{1}$ Náo foi à toa que Jason Stanley escolheu a frase do ideólogo nazista Joseph Goebbels como epígrafe do livro. A opção está plenamente em acordo com o espírito da obra aqui resenhada, na medida em que o autor pretende sublinhar o potencial destrutivo da comunicação, quando substanciada em ideologias falhas (flawed ideologies), para um regime democrático e as promessas que este pretende cumprir.

A tradição democrática sustenta que os cidadãos mantêm a prerrogativa do julgamento com respeito às decisóes coletivas, decisóes estas associadas aos mecanismos de formação da opiniáo e da vontade democrática. A democracia guarda, portanto, uma relação direta com a possibilidade de livre comunicação entre os cidadãos, determinada por um equilíbrio entre liberdade e outros valores que lhes são igualmente caros. Ao reconhecer o papel fundante da livre expressáo de ideias para o regime democrático, emerge como um problema o impacto de certos discursos para o "valor equitativo das liberdades políticas". ${ }^{2}$

Stanley chama a atençấo para dois fatos relacionados à contestação política, que, por vezes, nos passam despercebidos. Primeiro, o fato de as reivindicaçóes de grupos desprivilegiados serem frequentemente desconsideradas, a despeito da solidez de seus argumentos. Segundo, os grupos carentes de recursos encontram obstáculos à sua ação política, que não derivam meramente da carência de recursos, mas sim da percepção e da autopercepção de que não têm o conhecimento necessário, ou a autoconfiança exigida, para participar do processo deliberativo. Esses grupos seriam vítimas de uma forma de injustiça epistêmica, uma vez que, para levar adiante as suas reivindicações, devem superar barreiras que outros grupos não enfrentam (pp. xvii-xviii).

Haveria uma espécie de círculo vicioso, em que sociedades marcadas por profundas desigualdades favorecem a ascensão de ideologias falhas, que, por sua vez, contribuem para a reprodução e o aprofundamento daquelas desigualdades. Ao se debruçar sobre a "propaganda", Stanley pretende explicar (a) o que ela é, (b) por que ela importa, e (c) os mecanismos que a tornam efetiva na deliberação pública. How propaganda works está dividido em sete capítulos (além da Introdução e Conclusão), que podem ser agrupados da seguinte maneira: (i) os capítulos 1 e 2, 5 e 6 são dedicados à definição dos termos do debate a partir da filosofia política clássica e contemporânea; (ii) o capítulo 3 faz um diagnóstico do problema no que toca à teoria democrática e as democracias contemporâneas; e (iii), no capítulo 7, encontramos um estudo de caso sobre as diretrizes da política educacional estadunidense, que ilustra os argumentos expostos anteriormente.

Como sói acontecer em uma resenha, não será nosso objetivo aqui explorar a fundo todos os pormenores dessa rica obra de teoria política. A fim de trazer ao público as principais contribuiçốes de Stanley para pensarmos o problema da comunicação na democracia, vamos nos debruçar sobre os pontos que nos parecem mais agudos para os debates que ora se apresentam em áreas como as ciências sociais, a filosofia e o direito.

Desde os clássicos do pensamento helênico, conhecemos as diversas objeçóes a certo tipo de discurso, associado, à época, à participação dos demagogos na política. ${ }^{3} \mathrm{Da}$ filosofia política clássica à ciência política moderna, ganharam destaque as consequências negativas da demagogia para a estabilidade dos regimes políticos. Na Grécia Antiga, Platão e Aristóteles assistiram à derrocada da democracia, fazendo-se críticos contumazes de uma 
forma de retórica em que as palavras eram usadas antes para encobrir, do que para revelar. Sob a égide da livre expressão de ideias, as democracias liberais permitem a veiculação de inúmeros tipos de discurso, a despeito dos riscos que determinados conteúdos representam para a democracia e as promessas de igualdade que lhe sustentam. A questão teórico-normativa mais relevante para a democracia liberal, nesse contexto, se refere ao fato de que o valor da liberdade, tão caro a essa forma de governo, pode criar constrangimentos à sua plena realização. Sendo o propósito do livro analisar os tipos de propaganda que ameaçam a democracia liberal, nada mais natural que se lance luz sobre os discursos que vão de encontro a ideais associados ao regime democrático, como liberdade, igualdade e tolerância (pp. 72-73). ${ }^{4}$

Stanley remete esses ideais à ideia de razão pública. ${ }^{5} \mathrm{O}$ dever de civilidade associado à razão pública seria fundamental à democracia liberal, pois, apenas mediante um debate "justo e honesto", podemos chegar a decisões políticas efetivamente legítimas. Um sistema político liberal protege a liberdade de seus cidadãos uma vez que veda decisóes vinculantes arbitrárias, isto é, que não contem com o assentimento racional de todos aqueles afetados por tais decisóes (pp. 88-89). ${ }^{6}$ A propaganda, segundo Stanley, afeta o processo deliberativo, que é a base de sustentação de um sistema político democrático, independentemente de consideraçóes sobre a correção dos resultados gerados a partir desse processo, pois decisóes que emergem de processos contaminados por uma forma perniciosa de comunicação não seriam capazes de reivindicar legitimidade (pp. 90-91).

Assim, a ideia de razão pública emerge à medida que refletimos sobre os ideais que devem servir de guia para as normas que regulam a deliberação. Perguntamo-nos, então, que critérios podem ser usados para definir se e quanto um processo como esse deve ser considerado "justo e honesto". Stanley nos oferecerá três diretrizes, que podem ser usadas ao avaliarmos o processo deliberativo que dá origem a normas válidas universalmente para a comunidade política: (1) todos os debates no fórum político público devem ser orientados por uma norma de racionalidade teórica, ou seja, em reivindicaçóes legitimamente justificadas, que contribuem para uma decisão racional sobre a temática sob escrutínio; (2) eles devem se guiar pela razão prática aliada ao véu de ignorância (essa norma exige ao menos alguma empatia entre os que tomam parte na deliberação pública e nas decisóes vinculantes); e (3) a argumentação pública deve se guiar por uma norma de razoabilidade ou de igual respeito às perspectivas de todos os participantes, isto é, a nossa participação na deliberação pública deve ser orientada pela justificabilidade dos argumentos mobilizados na defesa de determinada posição (pp. 94-110). ${ }^{7}$

Sabemos que os "significados sociais" que compartilhamos e que, de certo modo, criam as estruturas de expectativas de nosso comportamento em sociedade são ubíquos e muitos deles carregam um conteúdo expressamente iliberal, tornando o uso de determinadas palavras e expressóes, com o seu sentido subjacente, instrumentos de exclusão e silenciamento de vários grupos na sociedade. Desse ponto de vista, parece tarefa impossível que a comunicação venha a se aproximar em qualquer tempo do ideal de razão pública. Uma forma de mensurar a compatibilidade de uma sociedade com os ideais democráticos é mediante uma análise do grau em que aqueles que se engajam no discurso público se comprometem com o "dever de civilidade" identificado com a razão pública, e a medida em que são encorajados a fazê-lo (pp. 167-173).

Haja vista a complexidade da deliberação pública no cotidiano das democracias liberais, Stanley aventa que a maneira mais apropriada para lidar com o problema da propaganda e das ideologias falhas seja a nossa capacidade de refletir e sermos sensíveis aos impactos de ideologias falhas em nosso próprio sistema de crenças. ${ }^{8}$ Contudo, há um problema adicional que merece destaque nessa análise, a saber, o tipo de sociedade ou de estrutura social que favorece a emergência e o espraiamento de ideologias falhas e as suas consequências negativas. Segundo Stanley, sociedades marcadas por desigualdades mais ou menos profundas são mais propícias para a ascensão de discursos propagandísticos que são nocivos à igualdade democrática (pp. 176-177).

O sucesso da propaganda, sugere o autor, depende da presença (i) de um sistema de crenças resistente às evidências que possam lhe contradizer e 
(ii) de crenças que, sendo resistentes à evidência, são também falhas em algum sentido. No quinto capítulo, Stanley busca evidenciar, valendo-se da linguagem humana, as crenças que seriam "céticas em relação aos sentidos”. Ao contrário de Hume, que se preocupa sobretudo com o modo pelo qual uma psicologia individual falha dá origem a uma crença ideológica também falha, Stanley lança luz sobre o mecanismo pelo qual estruturas sociais falhas, ou arranjos sociais injustos, podem ter o mesmo efeito, com consequências nefastas até mesmo para a forma como determinados grupos enxergam a si mesmos enquanto membros do corpo social.

Não raro, encontramos na tradição filosófica uma distinção entre crenças ideológicas e crenças regulares. O fator a distanciá-las seria a possibilidade de revisão, característico das últimas, mas não das primeiras. As crenças ideológicas impóem uma barreira à revisibilidade, por se associarem a certas práticas sociais ou identidades que temos razóes para valorizar. Há certas crenças necessárias ao nosso engajamento em uma comunidade, mesmo que, por vezes, a nossa adesão a elas seja mais ou menos hipócrita. Abandonar essas crenças significa deixar para trás a comunidade e parte do que com ela se identifica (pp. 185-187).

As crenças ideológicas que interessam ao autor são aquelas que derivam da estrutura social e que resultam em comportamentos que, à luz de evidências disponíveis, poderiam ser considerados irracionais. Para ele, tais comportamentos muitas vezes são o resultado de estruturas sociais injustas, de violência simbólica e outras formas de desigualdade que têm impacto significativo sobre a democracia. ${ }^{9}$ Chegamos aqui a um ponto crucial de seu argumento, a saber, a associação entre, de um lado, uma estrutura social injusta e, de outro, um sistema de crenças que organiza e justifica as práticas sociais, informado por uma ideologia falha:

[...] assim como uma crença pode ser ideológica em virtude de características estruturais da sociedade, que inibem a sua revisão, uma ideologia pode ser falha devido às características sociais falhas, que inibem a revisão racional de falsas crenças preexistentes, que preservam uma situação desejável a um grupo privilegiado (p. 199). ${ }^{10}$
Se as ideologias são compreendidas como uma espécie de roteiro que coordena as nossas expectativas, todos nós temos alguma ou algumas ideologias. Contudo, nem todas elas são ideologias falhas no sentido atribuído por Stanley. As ideologias falhas são aquelas que nos impedem de adquirir conhecimento, notadamente um tipo particular de conhecimento. Elas combinam uma forma de irrevisibilidade racional com certos defeitos epistêmicos (p. 200).

Interpretando as ideologias como barreiras que dificultam a aquisição de conhecimentos, Stanley avalia o que ele considera como uma das crenças mais deletérias à democracia liberal. Para ele, a ideologia do tecnicismo - e a meritocracia muitas vezes a ela associada - restringe, na deliberação pública, os argumentos tidos como legítimois àqueles que tenham validade científica. Uma forma de ideologia como essa rebaixa a participação dos cidadãos, sobretudo de grupos menos privilegiados, pois estes não seriam suficientemente qualificados para se engajar nas decisóes coletivas. Esse tipo de ideologia tende a reproduzir e intensificar o elitismo, criando um obstáculo instransponível à participação daqueles que se encontram em uma posição subalterna na sociedade (pp. 208-209). ${ }^{11}$

$\mathrm{O}$ argumento se desdobra em uma consideração sobre a desigualdade em pelo menos dois sentidos. De um lado, Stanley sugere que as desigualdades estruturais contribuem para o desenvolvimento e a consolidação de ideologias falhas, como as que afirmam que certas formas de desigualdades moralmente condenáveis não seriam injustas. De outro lado, e este é, talvez, o sentido mais importante, o autor afirma que a existência de ideologias falhas impóe enormes dificuldades para que políticas públicas orientadas pela justiça sejam viabilizadas na deliberação pública (p. 220).

Segundo Weber, toda forma de privilégio exige discursos de autolegitimação, os quais sustentam que os diversos tipos de superioridade estão associados ao mérito (apud Stanley, pp. 225-226). Uma posição como essa se associa ao que o pesquisador de Stanford, Claude Steele, afirma ser uma necessidade de mantermos uma permanente autoconcepção de nós mesmos como "pessoas boas e apropriadas”. Não seria implausível sugerir, portanto, que a exigência de um discurso de autoafirmaçáo por 
parte daqueles que detêm um quinhão maior de recursos na sociedade poderia aparecer como uma ideologia falha, que justifica a dominação opressiva sobre outros (idem, ibidem). ${ }^{12}$

Em sociedades marcadas por desigualdades profundas, os que se encontram em uma posição subalterna são oprimidos em diversos sentidos. Nesse contexto, uma ideologia falha pode ser responsável por impedir que tais grupos percebam a injustiça de sua condição e por evitar que ajam no sentido de modificá-la. A resistência a tais crenças envolve o que Kristie Dotson denominou "mudanças de terceira ordem", que dependem do controle de certos recursos hermenêuticos, que estarão tão menos disponíveis quanto maior a desigualdade uma forma de "injustiça contributiva" (apud Stanley, p. 237). Injustiças como essa são verificáveis mesmo em sociedades nas quais há acesso a fontes alternativas de informação e uma cultura política pluralista (pp. 237-238).

A dificuldade de superar as barreiras impostas pela estrutura social foram denominadas por Claude Steele e Joshua Aronso de "ameaça de estereótipo", isto, é "a ameaça situacional imediata que deriva da ampla disseminação de estereótipos negativos sobre um grupo" (apud Stanley, p. 240). ${ }^{13}$ Em outras palavras, esses autores indicam que certos tipos de preconceito são incorporados às crenças dos membros de grupos marginalizados como uma forma de "cognição protetiva de identidade" (idem, ibidem). Está longe de ser uma conclusão inédita a de que os grupos privilegiados acabam por controlar também as narrativas hegemônicas na sociedade. Em diversas circunstâncias, a superioridade será justificada pelo ideal meritocrático, o que permite aos grupos privilegiados combinar autoridade epistêmica e autoridade prática, colocando os demais membros da sociedade em uma situação de desvantagem epistêmica em discussões acerca de temas significativos, como a própria distribuição dos benefícios advindos da cooperação social (pp. 251-266).

No último capítulo, Stanley passa a analisar um caso em que podemos identificar a eficácia prática de tais ideologias. O sétimo capítulo tem, então, duas pretensões, a saber: (i) fazer uma descrição das principais características da ideologia das elites, e (ii) evidenciar a sua função na reforma do ensino secundário nos Estados Unidos na década de 1920. Stanley argumenta que o sistema educacional estadunidense vem sendo organizado de acordo com uma ideologia promovida e reproduzida no nível das elites. Segundo essa ideologia, as pessoas seriam desiguais e, portanto, a educação deveria oferecer a cada um os recursos necessários ao cumprimento de sua função na estrutura social. Como argumenta Dewey, a diferença no sistema educacional revelaria uma distinção mais profunda entre os membros de grupos que deveriam ser "livres" e os que deveriam ser "servis" (apud Stanley, p. 276). Nesse aspecto, o sistema educacional, que poderia promover maior igualdade de oportunidades, tende a aprofundar as desigualdades ora existentes. As elites, portanto, adquirem uma espécie de controle social sobre as camadas negativamente privilegiadas, uma forma de dominação por meio do controle das normas sociais (pp. 277-278). ${ }^{14}$

A percepção da educação como um instrumento para tornar a sociedade mais "eficiente" logo se apropriou da interpretação que sugeria a necessidade de se distinguir entre uma "educação liberal", apropriada aos que poderiam liderar a sociedade, e um "ensino prático" para aqueles que deveriam saber lidar com as necessidades materiais (p. 280). Nessa perspectiva, foi criada, em 1912, a Comissão para a Reorganização da Educação Secundária, cujo documento principal, que serviria de parâmetro, dali em diante, para a estrutura do sistema educacional estadunidense, que refletia, em grande medida, as ideias expostas acima. Segundo Stanley, o relatório, intitulado "Os princípios cardiais da educação secundária”, publicado após três anos de debate, era uma tradução da distinção platônica entre governantes e governados. De fato, em determinado momento, o documento sustenta que a democracia exigiria que a "atividade humana seja alçada a um alto nível de eficiência; e que nessa eficiência seja incluída uma avaliação da significância de tais atividades "e que um individuo escolha aquela vocação e aquelas formas de serviço social nos quais a sua personalidade seja mais capaz de se desenvolver e se tornar mais efetiva" (p. 284; grifo nosso). ${ }^{15}$

A oposição entre uma abordagem educacional, tal como advogada por Dewey, segundo a qual os estudos sobre a sociedade deveriam lançar luz sobre 
os obstáculos para o aprimoramento da sociedade, e uma visão segundo a qual eles deveriam servir ao controle social dos grupos menos privilegiados, segue ao longo do século XX. O que Stanley nos chama a atenção aqui é para a função, pouco valorizada, que teria sido desempenhada por diversos teóricos da educação, que contribuíram para a ascensão dessa última posição, encobrindo-a sob o véu da ciência e da técnica (p. 288).

$\mathrm{O}$ argumento central do livro, portanto, é de que desigualdades significativas de recursos propiciam práticas epistêmicas que erigem obstáculos à realização dos ideais da democracia liberal; tais obstáculos beneficiam aqueles que estão em uma posição privilegiada dessa distribuição desigual e, por isso, tendem a ser obscurecidos. Os grupos beneficiados se valem de instrumentos de propaganda a fim de impedir uma investigação mais profunda sobre a distância entre os ideais democráticos e a realidade social. Nesse sentido, o sistema educacional, assim como outros sistemas responsáveis pela construção simbólica da realidade social - como os meios de comunicação de massa - impossibilitam aos membros dos grupos negativamente privilegiados questionar as ideologias falhas que sustentam a estrutura de ônus e recompensas da cooperação social.

Movimentos sociais e lideranças políticas em diversos níveis agiram no esforço de desafiar a demagogueria sustentada em ideologias perniciosas que perpetuam práticas sociais que fortalecem e aprofundam as desigualdades - embora o avanço da igualdade tenha sido perceptivelmente insuficiente. Nesse sentido, ainda que não ofereça uma fórmula pronta para enfrentar os inúmeros problemas identificados ao longo do livro, Stanley nos apresenta um caminho profícuo, a partir do qual podemos compreender e criticar as justificativas, apresentadas por meio do discurso propagandístico, que contribuem para reproduzir e aprofundar graves injustiças encrustadas nas democracias contemporâneas.

\section{Notas}

1 No original: "This will always remain one of the best jokes of democracy, that it gave its deadly enemies the means by which it was destroyed". Todas as traduçóes desta resenha foram feitas pelo autor.

2 Nos diz Rawls que, às liberdades políticas, deve ser garantido um valor equitativo, ou seja, todos devem gozar dos direitos básicos e de oportunidades efetivas de exercê-las. Segundo Rawls, elas são importantes, não para promover os interesses humanos em qualquer sentido, mas para promover o bem dos cidadáos entendidos como pessoas livres e iguais (2011a, pp. 384-390).

3 Valendo-se dessa tradição, Stanley denomina de "demagogueria" o discurso propagandístico cujo efeito sobre a democracia considera negativo.

4 Cabe uma ressalva importante. Stanley admite, de saída, a ubiquidade da ideologia. Todos nós temos crenças ideológicas, isto é, crenças baseadas em conceitos que temos sobre nós mesmos e o nosso lugar no mundo. A crença na teoria evolucionista ou no criacionismo seriam, assim, igualmente ideológicas. $\mathrm{O}$ autor reconhece, portanto, náo haver um ponto arquimediano, uma postura absolutamente neutra, a partir da qual poderíamos avaliar, imparcialmente, se um discurso se enquadra ou não como propaganda e se ele é ou náo prejudicial à democracia. Enquanto uma teoria da ideologia, o livro pretende produzir conhecimento sobre a ideologia, o que não significa que ele tenha de ser, para tanto, desprovido de qualquer ideologia - o que seria, segundo o autor, infactível. Seja como for, a opção de Stanley por uma abordagem liberal é bem clara (p. 77).

5 O sentido atribuído pelo autor ao termo remete à obra de John Rawls (2011b), para quem o ideal de razão pública seria um "dever de civilidade", um padrão de argumentaçáo que deveria orientar os debates nos fóruns públicos políticos, como as supremas cortes, a arena legislativa e as campanhas eleitorais. Stanley estende este "dever" ao que Rawls denomina de "cultura de fundo".

6 Sem desconsiderar, todavia, casos em que um procedimento correto venha a levar a decisões injustas, bem como aqueles em que um procedimento incorreto leva a decisões que são boas para a comunidade - na interpretação de Stanley, John Rawls e Joshua Cohen seriam "procedimentalistas puros", cujo foco recai apenas sobre a correçáo do procedimento mediante o qual uma decisão foi tomada; ao passo que David Estlund e Hélène Landemore defenderiam uma versão epistêmica da teoria democrática, segundo a qual tanto o procedimento quanto o seu resultado importam (apud Stanley, 2016, p. 90). 
7 Stanley não deixa de admitir certas exceçóes, como as encontradas na obra de W. E. B. Du Bois ou na ação política de M. L. King Jr. Segundo o autor, determinadas formas de argumentação que não são racionais no sentido pensado acima podem ser necessárias para sobrepor os obstáculos impostos à realização dos ideais democráticos. Du Bois, por exemplo, sustenta que a arte negra poderia contribuir para o reconhecimento, através de um apelo à emoção, de que os negros merecem igual respeito como cidadãos e como sujeitos. Nesse caso, não há por que supor que haja alguma forma de manipulação da vontade racional, pois os argumentos não seriam fraudados ou enganosos, embora náo possamos afirmar que façam um apelo à racionalidade em sentido mais restrito do termo. Ademais, sugere Stanley, há razóes estruturais para considerarmos que esse tipo de argumento é fundamental para corrigir falhas na democracia liberal. Dado que determinados grupos são invisíveis aos olhos de seus concidadãos, que os temem ou os inferiorizam, não há método racional capaz de modificar essa situação, pois a invisibilidade também silencia as vozes dos excluídos (pp. 114-115).

8 Um dos papéis fundamentais da filosofia política, nos diz Stanley, é justamente o de evidenciar as ilusóes políticas que não nos permitem compreender a realidade social. A teoria que não se preocupe com a denúncia das ilusóes que obscurecem nosso olhar sobre a política, torna-se parte do mecanismo que produz tais ilusóes, pois constrói "a ilusão de que não há ilusão" (p. 33).

9 Nem toda crença associada a uma identidade ou a uma prática social será perniciosa à democracia. Ela não o será quando, por exemplo, estiver associada a valores como a tolerância, o pluralismo etc. As ideologias falhas são epistemologicamente incapacitantes, pois nos impedem de adquirir conhecimento sobre a realidade social, o que pode ter impactos negativos sobre nosso comportamento político (pp. 197-198).

10 No original: "[...] just as a belief can be ideological in virtue of structural features of society that inhibit its revision, so too can an ideology be flawed, because of flawed structural features of society that inhibit the rational revision of preexisting false belief, to preserve a desirable situation for a privileged group".

11 Não foi por mera coincidência que Habermas (1987) associou o domínio da técnica (enquanto ideologia) ao elitismo político, identificado por ele na crise do capitalismo tardio.
12 Há, segundo Stanley, uma ampla correlação, em vários países, entre riqueza e apoio a partidos de direita.

13 No original: "[...] the immediate situational threat that derives from the broad dissemination of negative stereotypes about one's group".

$14 \mathrm{Na}$ base desse processo, encontra-se uma divisão um tanto quanto questionável entre reflexão teórica e habilidades práticas.

15 No original: "human activity be placed at a high level of efficiency; and to that efficiency be added an appreciation of its level of the significance of these activities and that the individual choose that vocation and those forms of social service in which his personality may most develop and become most effective".

\section{BIBLIOGRAFIA}

HABERMAS, Jürgen. (1987), Técnica e ciência como "ideologia". Trad. Artur Morão. Lisboa, Ediçōes 70.

RAWLS, John. (2011a), O liberalismo politico. Trad. Álvaro de Vita. São Paulo, WMF Martins Fontes.

RAWLS, John. (2011b), "A ideia de razão pública revisitada”, in J. Rawls, O liberalismo politico, trad. Álvaro de Vita, São Paulo, WMF Martins Fontes. 